\title{
Die Heidelbergse Kategismus in sy eerste jare
}

\author{
JP Oberholzer \\ Universiteit van Pretoria
}

\begin{abstract}
The Heidelberg Catechism in its initial years

A short resumé of the circumstances and events around the birth of this important Protestant creed and its turbulent history during the first decades.
\end{abstract}

Die ondersoek na die ontstaan en eerste lotgevalle van die Heidelbergse Kategismus vorm in sigself 'n boeiende hoofstuk van die geskiedenis van hierdie leerboek en belydenisskrif. Danksy die indringende arbeid van etlike geslagte geleerdes beskik ons tans oor 'n rykdom van gegewens oor die bronne, die wording en vorming, en die teksgeskiedenis van die Kategismus (Vinke 1846; Ens 1857; Schotel 1863; Wolters 1864; Doedes 1867, 1876; Gooszen 1890, 1892; Lang 1907; Hesse 1938; Bakhuizen van den Brink 1940, 1976; Hollweg 1961; Goeters 1963, 1969; Visser 1983). Dit bly merkwaardig dat 'n geskrif wat betreklik laat op die Hervormingstoneel verskyn het, een van die betekenisvolste handboeke oor die Reformatoriese Geloofsleer en een van die wydsverbreide belydenisskrifte van die Gereformeerde Protestantisme geword het.

Weens veral politieke omstandighede het die hervorming in die Paltsgraafskap en Keurvorstedom aan die Ryn eers in Januarie 1546 gelei tot die eerste hervormingsmaatreël van die kant van die Keurvors, Frederik II (1544-1556). Sy edik oor die fakultatiewe bediening van die nagmaal onder albei gestaltes, godsdiensoefening en sakramentsbediening in die Duitse taal, opheffing van die misdwang vir die predikante en toelating van die priesterhuwelik het die weg gebaan vir evangeliese godsdiensoefening in Heidelberg en is gevolg deur maatreëls oor kloosterhervorming en 'n voorlopige kerkorde. Die evangeliese prediker, Heinrich Stoll wat professor in Heidelberg en later ook rektor was, het 'n groot aandeel gehad in die stille vordering van die Reformatoriese beweging ten spyte van die amptelike vertraging met hervormingsmaatreëls. Stoll het egter nie oor die dryfkrag beskik om werklik reformator van die Palts te word nie en pogings van Frederik II om so 'n reformator te vind, veral vir die universiteit, het nie geslaag nie. Die pogings van Stoll om tydens sy rektorskap die hervorming aan die universiteit deur te voer, het 
gestuit teen die weerstand van die Fakulteit Lettere en moes voorlopig laat vaar word. Die gang van die hervorming is bowendien belemmer deurdat Frederik hom tydelik aan die keiserlike Interim moes onderwerp na die Smalkaldiese oorlog.

Dit sou sy opvolger Otto Hendrik (1556-1559) toeval om deur die invoering van 'n kerkorde in 1556 en deur verskillende ander owerheidsmaatreëls die hervorming in die Palts 'n besliste koers te gee. Self was Otto Hendrik van Lutherse oortuiging, maar hy het 'n bemiddelende rol probeer speel tussen die strydende groepe in sy gesagsgebied, en onder sy bewind het die mees uiteenlopende rigtings ruimte gekry in die staatsdiens, kerk en universiteit. So is die drie leerstoele in die Fakulteit Teologie byvoorbeeld beset deur die gereformeerde Boquinus en die Lutherse Einhorn en Heshusen. Tilemann Heshusen was tegelykertyd Generaalsuperintendent van die kerk. Sy openlike pogings om die Lutheranisme teenoor die Gereformeerde Protestantisme in die Palts gevestig te kry, het sterk weerstand ontvang van die diakenpredikant Wilhelm Klebitz en die Nederlander Stephan Sylvius. Hulle het in twee akademiese disputasies wat onder voorsitterskap van Petrus Boquinus plaasgevind het, sterk aanvalle gemaak op Heshusen tot verleentheid van die rektor, die gereformeerdgesinde Thomas Erastus, medikus. Toe Heshusen aan die universiteit die nederlaag ly teenoor die stellings van Klebitz en Sylvius, het hy hom gewend tot die kansel. Die stryd het gegaan oor die nagmaal, en het spoedig gelei tot die afsetting van sowel Heshusen as Klebitz deur keurvors Frederik III.

Die keurvors was by sy bewindsaanvaarding reeds 'n oortuigde Protestant, daarin aangemoedig en bygestaan deur sy vrou Maria, dogter van die markgraaf van Brandenburg-Kulmbach. Die nagmaalstryd, waarin hy aanvanklik beland het met die oog op vrede in sy gesagsgebied, sou hom spoedig daartoe bring dat hy die gereformeerde rigting in die Protestantisme met vuur sou aanhang en bevorder. Direk na die ontslag van die twee hooffigure in die stryd op 16 September 1559 het hy die advies van Philippus Melanchton in Wittenberg oor die saak gevra. Melanchton het vinnig gereageer, en sy judicium oor die nagmaalstryd was reeds op 18 Oktober beskikbaar (Melanchton 1560). Hy het die optrede van Frederik goedgekeur, die nagmaalsleer van Heshusen verwerp, en 1 Korintiërs 10: 16 ('Die beker van danksegging waarvoor ons God dank, is dit nie die gemeenskap met die bloed van Christus nie? Die brood wat ons breek, is dit nie die gemeenskap met die liggaam van Christus nie?') aan die hand gegee as 'n formule waarmee daar eenheid verkry kon word. Mede vanweë hierdie advies van Melanchton maar ook op grond van die uitkoms van die nagmaalsdisputasie wat in Junie 1560 plaasgevind het tussen twee teoloë van Weimar en twee van Heidelberg, naamlik Boquinus en Erastus, het Frederik tot die oortuiging gekom dat die gereformeerde nagmaalsopvatting die regte is. Daarna het Frederik 'n hele aantal streng Lutherse 
predikante afgesit en die advies van Melanchton in druk laat verskyn. Dit was veral Thomas Erastus wat die Paltse nagmaalsopvatting duidelik sou formuleer in twee geskrifte, naamlik sy Gründlicher Bericht, wie das Wort Christi: Das ist mein Leib etc. $z u$ verstehen, wat waarskynlik in 1562 gedruk is, en daarna die bekende Büchlein vom Brotbrechen of, soos die titel oorspronklik gelui het, Erzelung etlicher Ursachen, warumb das hochwirdig Sacrament des Nachtmals unsers Hernn und Heylants Jhesu Christi nicht solle ohne das brodbrechen gehalten werden, wat begin 1563 saam met die Kategismus die lig gesien het (Gooszen 1892: 218).

Skynbaar was dit die keurvors self wat tot die insig gekom het dat leer en lewe in die Palts net deur middel van 'n kategismus hervorm sou kon word. Volgens alle gegewens was die Kategismus van Luther die eerste Protestantse leerboek van hierdie aard. Teen 1563 was daar verskillende dergelike leerboeke in die Palts in gebruik. Genoem word die Kinderkategismus van Johannes Brenz, die Examen Ordinandonum van Melanchton, die Klein Kategismus van Luther, die Regensburgse Kategismus van 'n anonieme persoon en die Straatsburgse Kategismus (Goeters 1969: 40). Dit was die bedoeling van keurvors Frederik dat hierdie gebrek aan eenvormigheid vervang moes word met 'n saaklike en duidelike leerboek wat sou sorg vir deeglike kategese. Soos hy dit self gestel het: 'Die jeug moet van die begin af in die eerste plek opgevoed word in die suiwere en ook eenvormige leer van die Heilige Evangelie en in die regskape kennis van God, en voortdurend daarin geoefen word'. Opdrag in hierdie verband is gegee aan die agt-en-twintig jarige Zacharias Ursinus, opvolger van Caspar Olevianus in die leerstoel Loci Communes. Die twee ontwerpe wat deur Ursinus voorberei is, is vandag nog beskikbaar en getuig van die besondere vermoê van hierdie jongman. Die langer ontwerp wat in 1584 gepubliseer is onder die titel Catechesis hoc est Rudimenta Religionis Christianae en in die Reúteruitgawe van Ursinus se werke in 1612 onder die titel Catechesis, Summa Theologiae, het bestaan uit 323 vrae en antwoorde in Latyn. Die korter ontwerp was in Duits en het 108 vrae en antwoorde bevat. Van hierdie ontwerp is slegs die Latynse vertaling wat in die nagelate werke van Ursinus verskyn het, bekend (Reuter 1612). Hierdie korter ontwerp was onmiskenbaar die primère bron van die Heidelbergse Kategismus. Die Kategismus self, wat vorm, volgorde en bewoording betref, sluit nou aan by die ontwerp van Ursinus, maar kan nie sonder meer as sy werk beskou word nie. Ons kan hierdie Kategismus trouens beskou as van die mees suksesvolle kommissiewerk wat daar nog gedoen is. Volgens die karige berigte wat daaroor bestaan, was die keurvors self voorsitter van die kommissie wat in die laaste maand van 1562 die Kategismus sy huidige vorm en inhoud gegee het (Goeters 1963: 14; 1969: 40, 41). Geduldige en indringende navorsing het aan die lig gebring dat Ursinus by die opstel van sy ontwerpe, en die 
kommissie by die finale vormgewing van die Kategismus, talle reformatoriese geskrifte geraadpleeg en aangehaal het. Genoem word die Geneefse kategismus van Calvyn, die Zürichse kategismusse van Leo Jud, die kategismusse van Martin Micron en Johannes a Lasco, 'n belydenis van Beza en geskrifte van Calvyn, Bullinger en Melanchton (Goeters 1963: 13, 14; 1969: 41). Dit verklaar meteen waarom die Heidelbergse Kategismus die gereformeerde teologie in sy breë spektrum verteenwoordig. Die Kategismus was nie alleen bedoel as leerboek nie maar ook as belydenis en as apologie teenoor die talle tydgenootlike teologiese twispunte. Daarvan is die heftige aanvalle en die stortvloed van kritiek wat op die verskyning van die Kategismus gevolg het, getuie.

Die gebruik van Skrifverwysings aan die rand of onderkant elke antwoord ter stawing van die betrokke gedeelte, was teen dié tyd ook reeds 'n gevestigde gebruik in sommige kategismusse en het op aandrang van die keurvors deel geword van die gestalte van die Heidelbergse Kategismus. Die eerste uitgawe, waarvan die voorrede deur die keurvors gedateer is 19 Januarie 1563, het waarskynlik vroeg in Februarie sy verskyning gemaak en het dadelik wye verbreiding geniet (Wolters 1864). In die Duitse uitgawe was die vrae ongenommerd en het die Skrifverwysings geskied met vermelding van die hoofstukke alleen, omdat teen hierdie tyd daar nog nie 'n Duitse Bybel met versnommers beskikbaar was nie. In 'n tweede uitgawe wat teen einde Februarie of begin Maart verskyn het, is daar enkele uitbreidings gemaak. Vraag en antwoord 36 is uitgebrei en die Skrifverwysings is hersien en aangevul. Daarnaas is daar ook nog 'n nuwe vraag en antwoord opgeneem oor die verskil tussen die nagmaal en die mis, die huidige vraag en antwoord 80 (Vinke 1846).

In die derde uitgawe, wat teen einde Maart of begin April van die pers af gekom het, is antwoord 80 verder uitgebrei en verskyn dit in sy huidige vorm. Hierdie sogenaamde derde uitgawe wat ook die grondslag vorm van my eie teksuitgawe, was in werklikheid 'n heruitgawe van die tweede met slegs enkele wysigings (Heidelberger Katechismus 1563; Schaff, s d; Oberholzer 1986).

In die loop van 1563 het reeds verskillende vertalings van die Kategismus verskyn. Die keurvors het in sy voorrede by die eerste uitgawe al gemeld dat hy die Kategismus in Duits sowel as Latyn laat opstel het. Volgens berigte was daar twee Latynse uitgawes in 1563, maar tot dusver het slegs een aan die lig gekom, met 'n vraag 80 wat ooreenkom met dié in die derde Duitse uitgawe (Heidelberger Katechismus 1563; Oberholzer 1986). Wie egter noukeurig aandag gee aan die ooreenkoms en verskil tussen die Duitse en Latynse weergawes van 1563 , kom tot die gevolgtrekking dat die Latynse uitgawe nie as 'n vertaling van die Duitse in alle opsigte beskou kan word nie, maar eerder as 'n selfstandige gestalte naas die Duitse. 
Twee Nederlandse vertalings van die Kategismus is in die loop van 1563 gemaak, die eerste deur ' $n$ anonieme persoon uit die tweede uitgawe, en die tweede deur Petrus Datheen uit die derde uitgawe van die Kategismus. Uit die vertaling van Datheen is dit duidelik dat hy sowel die Duitse as Latynse teks vir vertaling geneem het en dat hy na eie keuse by een van die twee aangesluit het, en enkele kere ook nog sy eie weg gegaan het (Doedes 1881). Die vertaling van Datheen is gemaak ten behoewe van die Nederlandse vlugtelinggemeente in Frankental in die Paltz, en die ouer Nederlandse vertaling wat in Emden verskyn het, was vermoedelik vir die gebruik van die gemeente aldaar. Ook nog in 1563 het 'n vertaling in Saksies verskyn, dit is die sogenaamde Nederduitse dialek van destyds.

Sy finale gestalte het die Kategismus bereik met die publikasie van die Paltse Kerkorde in Desember 1563 (Hesse 1938; Goeters 1969; Bakhuizen van den Brink 1940, 1976). In werklikheid is daar aan die bewoording van die onderskeie vrae en antwoorde weinig verander tussen die eerste en hierdie vierde uitgawe. Afgesien van klein verbeterings in spelling en woordorde het die volgende wysigings plaasgevind: 36 Vraag: empfengnusz und geburt Christi, Ant. Das er unser mittler ist und mit seiner unschuldt; 44: abgestiegen in plaas van abgefaren; 75: + zu seinem gedechtnisz; 78: abendmal in plaas van nachtmal; 79: leiden und gehorsam in plaas van leiden und sterben; 80: Tweede uitgawe: 'Das abendmal bezeuget uns, dasz wir volkomene vergebung aller unserer sünden haben, durch das einige opffer Jesu Christi, so er selbst ein mal am creutz volbracht hat. Die Mess aber lehret dass die lebendigen und die todten nit durch das leiden Christi vergebung der sünden haben, es sei dan, dass Christus noch teglich für sie von den Messpriestern geopffert werde: Und ist also die Mess im grund ein abgöttische verleugnung dess einigen opffers und leidens Jesu Christi'. Derde uitgawe: Die antwoord soos hy nou is. 90: Hertzliche freud in Gott durch Christum; 117: alles, das er uns zu bitten befohlen hat.

Die Skrifverwysings het tussen die eerste en die tweede uitgawe 'n grondige hersiening en uitbreiding ervaar. Dat die Latynse teks nie bloot 'n vertaling van die Duitse was nie, blyk ook nog daaruit dat die Skrifverwysings by die Latynse teks veel meer is as dié in die derde uitgawe van die Duitse teks en bowendien ook nog skynbaar onafhanklik van dié in die Duitse teks opgestel is. Dit het onder andere tot gevolg gehad dat die Skrifverwysings in die vierde Duitse uitgawe, die in die Kerkorde van 1563, verder uitgebrei is. Die Kategismusteks in die Kerkorde het die textus receptus vir die Duitse gestalte geword, en die stof is op twee wyses ingedeel, naamlik in Sondagsafdelings en in voorlesingseenhede. Die indeling van die 129 vrae en antwoorde in 52 Sondagsafdelings het ten doel gehad dat die volledige Kategismus met verloop van ' $n$ jaar in die prediking behandel sou kon word. Vir die doel is in die voorrede by die Kerkorde vasgestel dat daar elke Sondagmiddag 
kategismusprediking sou wees waarin die Kategismus nie alleen uitgele moes word deur die voorganger nie, maar waarin die katkisante ook geleentheid moes he om die betrokke getal vrae vir die Sondag te antwoord. Daar is verder in die voorrede vasgestel dat die hele Kategismus om die tien Sondae in die oggenderediens voorgelees moes word. Vir dié doel is die Kategismus verdeel in nege voorlesingseenhede of Lectios. Die voorlesing op die tiende Sondag het tot inhoud gehad die sogenaamde standspreuke wat van die vierde uitgawe af agter in die Kategismus opgeneem is. Dié bepalings in die Kerkorde wou verseker dat die inhoud van die Kategismus so wyd as moontlik en so gereeld as moontlik onder die aandag van almal sou kom. In die eerste drie uitgawes was daar aan die einde ook nog 'n 'Opgawe van die vernaamste tekste soos dit ordelik in die voorgaande Kategismus verklaar is', bedoel as ' $n$ kort samevatting van die inhoud van die Kategismus. Hierdie opgawe is in die vierde uitgawe vervang met 'n kort samevatting van die Kategismus.

Die Kategismus sowel as die Kerkorde in sy geheel was 'n uitgesproke en duidelike keuse vir die gereformeerde vorm van Protestantisme en het ten doel gehad die totale hervorming van die openbare lewe in die Palts. Soos te verwag, het dit van Lutherse kant ernstige besware te voorskyn geroep. Die eerste jare na publikasie van die Kategismus is in beslag geneem deur heftige skrywes en disputasies wat uiteindelik uitgeloop het op 'n poging om op die Ryksdag van Augsburg 1566, die Palts uit te sluit van die godsdiensvrede van 1555 . Hierdie bedreiging is afgeweer danksy die hulp van die vorste van Sakse en Hesse. Keurvors Frederik het hom op hierdie Ryksdag as 'n ware reformator betoon. Hy sou onder andere daar gesé het: 'Wat my Kategismus betref, ek staan by hom. Hy is in die kantlyn so met fondamente uit die Heilige Skrif verskans dat hy nie aangetas kan word nie en hy sal, so hoop ek, met God se hulp ook verder nie aangetas kan word nie. Origens troos ek my daarmee dat my Heer en Heiland Jesus Christus my saam met al sy gelowiges die sekere belofte gegee het dat alles wat ek vir sy eer of sy Naam sal verloor, my in die wêreld wat kom, honderdvoudig teruggegee sal word.'

Buiten die Palts sou die Kategismus 'n ware veroweringstog he: Oranje-Nassau 1581, Niederrhein 1586, Lippe 1600, Mark 1610, en verder Wittgenstein, Braunfels, Hanau, Brandenburg, Hongarye en die Nederlande. Na die besluite van die Dordtse Sinode in 1619 het bygekom Bremen, Hesse, Tecklenburg, Bentheim, Lingen, Anhalt, die Switserse kantons St Gallen, Aargau en Schaffhausen, die gereformeerde gemeentes in Bohemiě en Pole, en later Amerika en Suid-Afrika. Wat betref die inrigting van universiteite, katkisasie, kinderopvoeding in skool en ouerhuis het die Kategismus die totale volkslewe hervorm veral in Holland, Niederrhein en Hongarye (Graffmann 1959; Lippe 1938: 148). 
Binne die Palts sou die lotgevalle van die Kategismus egter wisselvallig wees. Voor die dood in 1576 van Frederik III die Vrome, soos 'n dankbare nageslag hom genoem het, is die Kategismus en die volledige kerkorde telkens herdruk, onder andere in 1565, 1567, 1569 (Kerkorde), 1566, 1570 (Kategismus Latyn), 1573 (Kategismus Duits). Frederik se oudste seun, Lodewyk VI, wat hom opgevolg het, is egter deur sy moeder Maria en aan die hof van Markgraaf Filibert van Baden streng Luthers opgevoed en het alles in die werk gestel om die Palts te laat terugkeer na die Lutherse protestantisme. Omdat hy hom teen hierdie maatreëls verset het, is die kerkleier Olevianus eers onder huisarres geplaas en later verban. Dit is in Oktober 1577 gevolg deur die ontslag van Ursinus, terwyl die drie teologieprofessore Boquinus, Tremellius en Zanchius op 6 Desember 1577 ontslaan is.

$\mathrm{Na}$ Lodewyk se dood in 1583 is hy opgevolg deur Johan Casimir, sy broer, wat aanvanklik (1576-1583) hertog van Pfalz-Lautern was, en in 1583-1592 ook as administrateur van die Palts opgetree het. Johan Casimir het die gereformeerde rigting van sy vader voortgesit, en publiseer al in $\mathbf{1 5 7 6}$ in Heidelberg, terwyl hy as stadhouer tydens sy broer se tydelike afwesigheid opgetree het, 'n herdruk van die Paltse Kerkorde. Tydens sy latere administrateurskap publiseer hy nog 'n herdruk, naamlik in 1585. Johan Casimir probeer dus van sy kant af om die Lutherse maatreëls van sy broer ongedaan te maak. In 'n voorskrif oor die geloofsbelydenisse wat deur kerkdienaars onderskryf moes word, word in 1586 vir die eerste keer die Heidelbergse Kategismus tot belydenisskrif verklaar.

Johan Casimir is na sy dood in 1592 opgevolg deur sy neef Frederik IV wat toe slegs sewentien jaar oud was. 'n Poging van sy oom Reichard van Pfalz-Zimmern om as regent die Palts na die Lutheranisme te laat terugkeer, is deur die prins self gestuit toe hy hom tot keurvors verklaar en die land se regering eenvoudig oorgeneem het. Die feit dat hy vroeg verloof is aan die dogter van Willem die Swyger het gehelp dat sy gereformeerde oortuiging voldoende steun gekry het. Ook Frederik IV publiseer 'n Kerkorde, naamlik in 1601. In hierdie kerkorde word vir die eerste keer twee Kategismuspreke in die stede op Sondagmiddae verorden, die eerste oor 'n Klein Kategismus en die volgende oor die Heidelbergse Kategismus. In die Heidelbergse Kategismus in hierdie Kerkorde verskyn die Lectio's nie meer nie, en is die Skrifbewyse opnuut bewerk. Met hierdie Kerkorde en die ander maatreëls van Frederik IV, is die organisasie van die kerk in die Palts op gereformeerde lees volvoer. Toe hy op ses-en-dertigjarige leeftyd sterwe, was sy seun Frederik V (16101632) nog minderjarig en het Hertog Johan II van Pfalz-Zweibrücken as regent opgetree. Johan was self gereformeerd en het geen verandering aan die kerklike politiek bewerk nie. 
Die dertigjarige oorlog (1618-1648) was vir die gereformeerde kerk in die Palts rampspoedig, maar talle maatreëls het bly staan, en toe ná die vrede van Wesfalië in 1648 die seun van Frederik V, Karel Lodewyk, die bewind in die Paits oorneem, het die Gereformeerde Protestantisme en die Kategismus sy laaste tydperk van voorspoed in die Palts belewe. Die Kerkorde is nogeens gepubliseer. Volgens die voorrede was dit reeds in 1652 gereed, maar volgens die titelblad is dit eers gedruk in die jaar 1665. Dit was hoofsaaklik 'n herdruk van die Kerkorde van 1601 (ChurPfalzische Kirchen- Ordnung 1665).

Ná Karel Lodewyk gaan die heerskappy oor die Palts oor na die Roomse vorste van Pfalz-Neuburg en word die Palts oorstroom deur Jesuĩete. Ten spyte van ernstige onderdrukking en vervolging het die gereformeerdes vasgehou aan hulle oortuiging en aan die Kategismus. Die verbod op die Kategismus is uiteindelik deur die keiser en die ryksdag self opgehef. Die Franse revolusie bring egter die finale slag. Die Palts hou op om selfstandig te bestaan en word onder buurlande opgedeel. Die Kategismus is uit sy tuisland verban, om eers teen die helfte van die vorige eeu weer daarheen terug te keer.

Wat Nederland betref, was die gang van die Kategismus 'n triomftog. Reeds in 1568 vereis die konvent van Wesel dat die ouderlinge instemming moes verklaar met die leer wat in die Nederlandse Geloofsbelydenis en die Kategismus vervat is (Documenta Reformatoria 1960: 185). In 1571 word dit deur die Sinode van Emden bevestig (Pont 1981: 103). Teen hierdie tyd het daar reeds talle drukke van die Kategismus in Nederlands verskyn (Nauta 1963: 48). Datheen se tweede vertaling van die Kategismus, dié van 1566 wat op enkele punte nogal wesenlik van dié van 1563 verskil (Doedes 1876: 44-47) het spoedig die textus receptus vir die Nederlandse wêreld geword, veral omdat dit van die begin af ingebind is by sy Psalmvertaling. Die Provinsiale Sinode van Holland en Zeeland, gehou in Dordrecht in 1574, bepaal dat alleen die Heidelbergse Kategismus in die kerke gebruik sal word, en dit is bevestig deur die Nasionale Sinode van Dordrecht 1578 waar spesifiek die Kategismus wat saam met die Psalms van Petrus Datheen verskyn, genoem word. In 1586 bepaal die Nasionale Sinode van Den Haag dat daar Sondae uit die Kategismus gepreek sal word, iets wat teen die tyd reeds op baie plekke plaasgevind het. Die Nasionale Sinode van Dordrecht 1618, 1619 het nie alleen by herhaling die status van die Kategismus as belydenisskrif bevestig nie, maar ook nog duidelike voorskrifte gegee oor die kategismusprediking.

Is besloten, dat dit artikel inzonderheid vernieuwd, en aan alle Predikanten, niet alleen in de steden, maar ook in alle dorpen, ernstiglijk en onder zware kerkelijke censuur gelast sal worden: Dat 
men des Zondags namiddags, altijd Catechetische predikatiěn zal doen, in welke de Heidelbergsche Catechismus, in onze Kerken aangenomen, na die orde verklaard wordh, gelijk in het voornoemd artikel gelast word en dat dese namiddag predikatiěn, om het klein getal toehoorders, dat in sommige dorpen zoude kunnen voorgewend worden, niet zullen mogen verzuimd of nagelaten worden, al is het, dat de Predikanten in het eerste voor weinig toehoorders, ja, maar alleen voor hunne Familien zouden moeten prediken (Ens 1857: 50-61).

Die Kategismus is ook in Bybeluitgawes opgeneem, en op dié wyse het hy talle herdrukke belewe. Hoewel die teks van tyd tot tyd hersien is, gewoonlik aan die hand nie alleen van die Duitse nie maar ook van die Latynse oorspronklike, het die Datheen-teks tot vandag toe basies behoue gebly, en die nuutste Afrikaanse vertaling van 1982 sluit steeds sterk aan by die Datheen-teks.

Omdat die volle verhaal van die Kategismus en sy herdrukke in Nederland en Suid-Afrika afsonderlike behandeling verdien, laat ek dit daar, en sluit af met enkele opmerkings oor die Skrifverwysings by die Kategismus. Dit kom voor asof van die begin af daar groter vryheid bestaan het ten opsigte van wysigings en uitbreiding of vermindering van die Skrifverwysings as wat daar bestaan het ten opsigte van wysigings aan die teks van die Kategismus. Die arbeid in 1563 wat Skrifverwysings betref, het neerslag gevind enersyds in die Duitse teks met die vierde druk as die voorlopig finale gestalte en andersyds die Latynse teks met ' $n$ eie stel Skrifverwysings. Van die kant van die Latynse teks het daar reeds in 1563, maar ook later sterk invloed uitgegaan op die Duitse teks. Tydens die bewind van Johan Casimir was daar groot aktiwiteite rondom die Skrifverwysings, heel waarskynlik omdat die volgehoue weerstand van Lutherse kant die gereformeerdes telkens gedwing het om verder in die Skrif te soek vir ondersteuning van die bewoording van die Kategismus. Sowel die Kerkorde van 1585 as die besondere kategismusuitgawes in Duits en Latyn rondom dié tyd vertoon sterk uitgebreide stelle Skrifverwysings en verskil nogal onderling heelwat van mekaar. Die groot sorg waarmee hierdie Skrifverwysings telkens hersien is, getuig van noukeurige aandag vir die belangrikheid daarvan. Daar het wel enkele uitgawes van die Kategismus verskyn waarin dit duidelik is dat die Skrifverwysings op ' $n$ agtelosige wyse gehanteer is, soos byvoorbeeld die van die Duitse teks wat in 1596 in Neustadt by Mattheus Harnisch gedruk is. Maar oor die algemeen is daar in die Duitse uitgawes groter nugterheid geopenbaar as in sommige Nederlandse uitgawes. Die twee tekste tot my beskikking wat in 1581 agter in die Deux Aes Bybel afgedruk is, een in Dordtrecht en die ander een in Delft, sluit betreklik nou aan by die stel Skrifverwysings van die 
Latynse teks van 1563. Die neiging in Nederland was egter om te streef na steeds meer verwysings. So het byvoorbeeld 'n uitgawe van 1595 seker tweekeer soveel Skrifverwysings as vroeëre uitgawes, terwyl die toppunt in Nederland bereik is met die Kategismus soos dit in 1615 in Thysius se Leere ende Order der Nederlandsche, soo duytsche als walsche, Ghereformeende Kerken verskyn het en wat in 1725 net so herdruk is deur Mattheus de Vries in Dordrecht. Thysius se self in 'n voorwoord dat hy die Skrifverwysings wat hy in vroeëre uitgawes naamlik die van 1563,1571, 1580, $1582,1591,1608$ en 1611 gevind het, saamgevoeg en uitgebrei het. Geen wonder nie dat daarna die gebruik meer en meer in swang gekom het om die kategismusteks sonder enige Skrifverwysings te publiseer. Ook wat die Latynse uitgawes betref, het die Skrifverwysings 'n neiging gehad om uit te brei, hoewel nie op dieselfde skaal nie. In die opsig neem die uitgawe wat in 1597 in Heidelberg verskyn het met 'n Griekse vertaling van die Kategismus deur Frederik Sylburgius en met ' $n$ voorwoord gerig aan keurvors Frederik IV deur Johannes Frederikus Gernandus Wetteranus, 'n besondere plek. Hierdie uitgawe bevat naamlik die stel Skrifverwysings wat ook voorkom in Ursinus se Prolegomena in Religionis Christianae Catechesin, quae in Ecclesiis et Scholis Palatinus traditus soos dit afgedruk is in die Opera Teologica van Ursinus wat deur Reuter in 1612 gepubliseer is. Hierdie stel Skrifverwysings is deur Rutgers oorgeneem toe hy in medewerking met Bavinck en Kuyper die formuliere van enigheid vir die Gereformeerde Kerke in Nederland moes bewerk, onder die indruk dat hy in die teks en skrifverwysings soos dit in die 1612-uitgawe voorkom, te doen het met die Latynse uitgawe (Rutgers 1913: 20). Soos ek elders aangetoon het (Oberholzer 1986: 97), is hierdie teks en Skrifverwysings van Rutgers op sy beurt oorgeneem vir die eerste Afrikaanse uitgawe van die Kategismus in 1936 en het die stel Skrifverwysings die aanvaarde geword wat sindsdien in Suid-Afrika gebruiklik is.

\section{Literatuurverwysings}

BAKHUIZEN VAN DEN BRINK, JN 1940. De Nederlandsche Belijdenis geschriften. Amsterdam: Uitgeversmaatschappij Holland.

BAKHUIZEN VAN DEN BRINK, JN 1976. De Nederlandsche Belijdenis geschrifien. Amsterdam: Uitgeverij Ton Bolland.

Chur-Pfalzische Kirchen-Ordnung, Wie es mit der Christlichen Lehr, Heiligen Sacramenten, und Ceremonien, in allen Kirchen der Churfüstlichen Pfalz gehalten werden soll. Wie dieselbe vor alters, und in Anno 1611 das letzte mahl publicin gewesen, und anjetzo bey Regierung des Durchleuchtigsten Fürsten und Herm, Herrn Carl Ludwigen, Pfalzgraffen bey Rhein, des Heil Röm Reichs Ertz 
Schatzmeysters und Churfürsten, Hertzogen in Bayern, etc., Auffs Newe, und dem obgedachten Exemplari ganz gleichformig nach gedruckt worden. (Gedruckt in der Churfürstlichen Statt Heydelberg. Anno MDC LXV.)

DOCUMENTA REFORMATORIA 1960. Teksten uit de geschiedenis van Kerk en theologie in de Nederlanden sedert de Henorming. Kampen: Kok.

DOEDES, JI 1867. De Heidelbergsche Catechismus in zijne eerste levensjaren 15631567. Utrecht.

DOEDES, JI 1876. Nieuwe Bibliographisch-Historische Ontdekkingen: Bijdragen tot de kennis van de ... Eerste Lotgevallen des Heidelbergschen Catechismus in het Nederlandsch ... Utrecht: Kemink \& Zoon.

DOEDES, JI 1881. De Heidelbergse Catechismus opnieuw overgezet, en volgens de vertaling van Datheen (Heidelberg 1563) opnieuw uitgegeven. Utrecht: Kemink \& Zoon.

ENS, Johannes 1857. Kort Historisch Bericht van de Publieke Schriften, rakende de leer en dienst der Nederduitsch kerken van de Vereenigde Nederlanden ... Kampen: $S$ van Velzen, Jr.

GOETERS, JFG 1963. Entstehung und Frühgeschichte des Katechismus, in Handbuch zum Heidelberger Katechismus, herausgegeben von Lothar Coenen. Neukirchen-Vluyn: Neukirchener Verlag des Erziehungesvereins GMBH.

GOETERS, JFG 1969. Die evangelischen Kirchenordnungen des 16. Jahrhunderts, herausgegeben von Emil Sehling, Bd 14: Kurpfalz. Tübingen: Mohr (Paul Siebeck).

GRAFFMANN, H 1959. s v. Heidelberger Katechismus. RGG.

GOOSZEN, MA 1890, De Heidelbergse Catechismus: Textus Receptus met toelichtende Teksten. Leiden: Brill.

GOOSZEN, MA 1892. De Heidelbergsche Catechismus en het boekje van de Breking des Broods, in het jaar 1563-64 bestreden en verdedigd. Leiden: Brill.

HEIDELBERGER KATECHISMUS 1563. Catechismus oder Christlicher Undericht, wie der in Kirchen und Schulen der Churfurstlichen Pfalz getrieben wirdt. Heydelberg: Johannes Meyer. [Catechesis Religionis Christianae, quae traditur in ecclesiis et scholis Palatinatus. Heydelberg: Michael Schirat, et Joannes Mayer. Zurich: Theologischer Verlag 1983 (Reprint-Ausgabe).]

HESSE, HK 1938. Kirchenordnung ..., in Bekenntnis-schriften und Kirchenordnungen der nach Gottes Wort reformienten Kirche. Hrsg von Wilhelm Niesel. 3. Auflage. Zollikon: Evangelischer Verlag.

HOLLWEG, W 1961. Neue Untersuchungen zur Geschichte und Lehre des Heidelerger Katechismus. Neukirchen: Neukirchener Verlag. 
LANG, A 1907. Der Heidelberger Katechismus und Vier Venwandte Katechismen. Leipzig: a Deichert'sche Verlagsbuchhandlung. (Nachf Georg Böhme.)

LIPPE, 1938. Der Heidelberger Katechismus ..., herausgegeben von der Lippischen Landeskirche. Essen: Essener Druckerei.

MELANCHTON, P 1560. Iudicium D Philippi Melanchtonis de controversia Coenae Domini, ad illustrissimum Principem ac DD Fridericum Comitem Palatinum Rheni, Sacri Romani Imperii Archidapiferum, Electorem, Bavariae Ducem, etc. Basileae 1560.

NAUTA, D 1963. Die Verbreitung des Katechismus, Übersetzung in andere sprachen, moderne Bearbeitungen, in Handbuch zum Heidelberger Katechismus. Hrsg von Lothar Coenen. Neukirchen: Neukirchener Verlag.

OBERHOLZER, JP 1986. Die Heidelbergse Kategismus in vier teksuitgawes. Pretoria: Kital.

OBERHOLZER, JP 1987. Die Heidelbergse Kategismus in Afrikaans: 'n Eerste blik op die eerste halfeeu. HTS 43, 86-98.

PONT, AD 1981. Die historiese agtergronde van ons kerklike reg. Pretoria: HAUM.

REUTER, Q 1612. D Zachariae Ursini Theologi Celeberrimi, sacrarum literarum olim in Academiâ Heidelbergensi \& Neustadianâ Doctoris \& Professoris fidelissimi, Opera Theologica quibus orthodoxae Religionis capita perspicue et breviter explicantur, haereses horum temporum solidé confutantur, ac aliae plurimae utilissimae materiae, enuditissime pertractantur: Partem antehac non edita, partim ex Germanicâ in Latinam linguam modó conversa, partim emendatiüs recusa, et illustrata: Tributa in Tomos Tres, Quorum Indicem á Praefatione pagina proxima exhibet: Edita studio et opera Quirini Reuteri. s. Th. D. et Professoris in Academia Heidelbergensi. Heidelbergae, Typis Johannes Lancelloti Acad. Typog. Impensis Iona Rosae. Anno 1612.

RUTGERS, FL 1913. De berijmde Psalmen met eenige gezangen in gebruik bij de Gereformeerde Kerken in Nederland; alsmede hare Formulieren von Eenigheid, met de drie oude Geloofsbelijdenissen, en hare Liturgie, met het Kort Begrip en den Ziekentroost. Maassluis: Uitgevers-genootschap 'Biblia'.

SCHAFF, P s d. The creeds of Christendom, with a history and critical notes, in three volumes. Fourth Edition. New York: Harper \& Brothers.

SCHOTEL, GDJ 1963. Geschiedenis van den oorsprong, de invoering en de lotgevallen van den Heidelbergschen Catechismus. Amsterdam: WH Kirberger.

VINKE, HE 1846. Libri Symbolici Ecclesiae Reformatae Nederlandicae. Traiecti ad Rhenum.

VISSER, D 1983. Zacharias Ursinus: The reluctant Reformer. His life and times. New York: United Church Press. 
Die Heidelbergac Kategismus in sy cerse jare

WOLTERS, A 1864. Der Heidelberger Katechismus in seiner ursprünglichen Gestalt. Bonn: Adolph Marcus. 